\title{
Transcription factor 7-like 2 (TCF7L2) variant is associated with familial breast cancer risk: a case-control study
} Barbara Burwinkel ${ }^{1,2}$, Kalai S Shanmugam ${ }^{1,2}$, Kari Hemminki ${ }^{2,3}$, Alfons Meindl ${ }^{4}$, Rita K Schmutzler ${ }^{5,6}$, Christian Sutter ${ }^{7}$, Barbara Wappenschmidt ${ }^{5,6}$, Marion Kiechle ${ }^{4}$, Claus R Bartram ${ }^{7}$ and Bernd Frank*1,2

\begin{abstract}
Address: ${ }^{1}$ Helmholtz-University Group Molecular Epidemiology, German Cancer Research Center, DKFZ, Heidelberg, Germany, ${ }^{2}$ Division of Molecular Genetic Epidemiology, German Cancer Research Center, DKFZ, Heidelberg, Germany, ${ }^{3}$ Center for Family Medicine, Karolinska Institute, Huddinge, Sweden, ${ }^{4}$ Department of Gynaecology and Obstetrics, Klinikum rechts der Isar at the Technical University, Munich, Germany, ${ }^{5}$ Division of Molecular Gynaeco-Oncology, Department of Gynaecology and Obstetrics, Clinical Center University of Cologne, Germany, ${ }^{6} \mathrm{Center}$ of Molecular Medicine Cologne (CMMC), University Hospital of Cologne, Germany and 7Institute of Human Genetics, University of Heidelberg, Heidelberg, Germany

Email: Barbara Burwinkel - b.burwinkel@dkfz.de; Kalai S Shanmugam - k.shanmugam@dkfz.de; Kari Hemminki - k.hemminki@dkfz.de; Alfons Meindl - alfons.meindl@lrz.tu-muenchen.de; Rita K Schmutzler - rita.schmutzler@uk-koeln.de; Christian Sutter - Christian.Sutter@med.uni-heidelberg.de; Barbara Wappenschmidt - barbara.wappenschmidt@uk-koeln.de; Marion Kiechle - marion.kiechle@Irz.tum.de; Claus R Bartram -Cr.Bartram@med.uni-heidelberg.de; Bernd Frank* - b.frank@dkfz.de

* Corresponding author
\end{abstract}

Published: 17 November 2006

BMC Cancer 2006, 6:268 doi:10.1186/147|-2407-6-268

This article is available from: http://www.biomedcentral.com/I47I-2407/6/268

(C) 2006 Burwinkel et al; licensee BioMed Central Ltd.

This is an Open Access article distributed under the terms of the Creative Commons Attribution License (http://creativecommons.org/licenses/by/2.0), which permits unrestricted use, distribution, and reproduction in any medium, provided the original work is properly cited.

\begin{abstract}
Background: The transcription factor 7-like 2 (TCF7L2) is a critical component of the $\mathrm{Wnt} / \beta$-catenin pathway. Aberrant TCF7L2 expression modifies Wnt signaling and mediates oncogenic effects through the upregulation of c-MYC and cyclin D. Genetic alterations in TCF7L2 may therefore affect cancer risk. Recently, TCF7L2 variants, including the microsatellite marker DGIOS478 and the nearly perfectly linked SNP rs 12233372, were identified to associate with type 2 diabetes.
\end{abstract}

Methods: We investigated the effect of the TCF7L2 rs 12255372 variant on familial breast cancer (BC) risk by means of TaqMan allelic discrimination, analyzing BRCAI/2 mutation-negative index patients of 592 German BC families and 735 control individuals.

Results: The $T$ allele of $r$ s 12255372 showed an association with borderline significance $(O R=1.19,95 \%$ C.I. $=1.01-1.42, P=0.04)$, and the Cochran-Armitage test for trend revealed an allele dose-dependent association of rs 12255372 with $\mathrm{BC}$ risk $\left(P_{\text {trend }}=0.04\right)$.

Conclusion: Our results suggest a possible influence of TCF7L2 rs 12255372 on the risk of familial BC.

\section{Background}

The transcription factor 7-like 2 (TCF7L2 alias TCF-4) gene product, a HMG box transcription factor, is part of the Wnt/ $\beta$-catenin signaling cascade, one of the key mechanisms of development and growth regulation in the cell
[1]. Grant et al. [2] have identified TCF7L2 as a novel candidate gene for type 2 diabetes and reported an association of the microsatellite marker DG10S478 within intron 3 . The associated tetranucleotid repeat was shown to have six alleles, namely alleles $0,4,8,12,16$ and 20 . The com- 
bined non-zero alleles of DG10S478 (referred to as X) were associated with an increased risk in three independent populations (Danish, Icelandic and US). The composite at-risk allele $\mathrm{X}$ was nearly perfectly correlated with the $\mathrm{T}$ allele of the single nucleotide polymorphism (SNP) rs12255372, while the G allele was linked to allele 0. Consequently, the rs12255372 $\mathrm{T}$ allele showed association with type 2 diabetes as well [2]. Recent studies have confirmed these findings, revealing strong association between rs 12255372 and type 2 diabetes in Dutch and US cohorts $[3,4]$.

There is accumulating evidence that aberrant activation of the Wnt/ $\beta$-catenin pathway has oncogenic effects $[5,6]$. Wnt signaling results in increased cytosolic levels of $\beta$-catenin which is released from the APC/Axin/GSK3 $\beta$ degradation complex and translocated into the nucleus to bind TCF7L2 $[1,2,6]$. The transcriptionally competent $\beta$-catenin/TCF7L2 complexes provoke an excessive expression of TCF7L2 target genes, such as the cyclin $D$ and $c-M Y C$ oncogenes, which is a common feature in human cancers, including breast cancer (BC). This supports the biological significance and clinical relevance of the Wnt/ $\beta$-catenin signaling pathway in carcinogenesis [7-9].

Given these facts, we investigated the effect of the rs12255372 polymorphism on familial BC risk.

\section{Methods}

\section{Study population}

We analyzed TCF7L2 rs 12255372 in 592 German familial $\mathrm{BC}$ cases and 735 control individuals. The $\mathrm{BC}$ cases comprised unrelated female index patients (19 to 87 years of age, median age 45 ) without mutations in the high-penetrance genes BRCA1 and BRCA2. Mutations in the open reading frame of $B R C A 1$ and $B R C A 2$ were excluded by applying denaturing high performance liquid chromatography (DHPLC) on all exons, followed by direct sequencing of conspicuous exons. Cases were collected during the years 1996-2005 through the Institute of Human Genetics (Heidelberg, Germany), the Department of Gynaecology and Obstetrics (Cologne, Germany) and the Department of Medical Genetics (Munich, Germany). According to the German Consortium for Hereditary Breast and Ovarian Cancer, $\mathrm{BC}$ cases were divided into six categories based on family history: (A1) families with two or more breast cancer cases including at least two cases with onset below the age of 50 years $(39.0 \%)$; (A2) families with at least one male breast cancer case $(0.7 \%)$; (B) families with at least one breast cancer and one ovarian cancer case (18.1\%); (C) families with at least two breast cancer cases including one case diagnosed before the age of 50 years (25.5\%); (D) families with at least two breast cancer cases diagnosed after the age of 50 years $(8.4 \%)$ and $(\mathrm{E})$ single cases of breast cancer diagnosed before the age of 35 years $(8.3 \%)[10,11]$. The TCF7L2 rs 12255372 analysis comprised one index case per family. DNA of further family members to evaluate segregation of the variant with $\mathrm{BC}$ risk was not available.

The corresponding control series consisted of healthy, unrelated and ethnically matched blood donors (26 to 68 years of age, median age 49) sharing the ethnic background with the patients. They were recruited in 2004 and 2005 by the Institute of Transfusion Medicine and Immunology (Mannheim, Germany). The study was approved by the Ethics Committee of the University of Heidelberg (Heidelberg, Germany), and written informed consent was obtained from all individuals.

\section{SNP selection}

Grant $e$ al. investigated five SNPs located within a $92.1 \mathrm{~kb}$ linkage disequilibrium (LD) block, encompassing parts of introns 3 and 4 and the whole of exon 4 [2]. We selected rs12255372 which was the most highly correlated SNP to the associated microsatellite marker DG10S478 $\left(\mathrm{r}^{2}=\right.$ 0.95 ) for genotyping.

\section{Detection of TCF7L2 rs 12255372 genotypes}

Genotyping of TCF7L2 rs 12255372 was performed by TaqMan allelic discrimination as described before [12]. Primers and probes were provided by the assay-by-design service (Applied Biosystems, Foster City, CA). The corresponding sequences are available upon request. Genotyping errors were excluded by re-genotyping $\geq 10 \%$ of the samples with a concordance rate of $100 \%$.

\section{Statistical analysis}

Genotype-specific odds ratios (OR), 95\% confidence intervals $(95 \%$ C.I.) and $P$ values were computed by unconditional logistic regression using the Statistical Analysis System software (Version 9.1.; SAS Institute Inc., Cary, NC). Hardy-Weinberg equilibrium test was undertaken using Pearson's goodness-of-fit chi-square test with one degree of freedom. Power calculation was carried out with the power and sample size software PS [13]. With the present sample size, we had a power of $80 \%$ at a significance level of 0.05 to detect an OR of $\geq 1.38$.

\section{Results and discussion}

The TCF7L2 rs12255372 T allele frequency of the controls (German Caucasians) was in accordance with those published in previous studies (Danish, Dutch, Icelandic and US Caucasians) [2-4], and the frequencies of rs12255372 genotypes were consistent with Hardy-Weinberg equilibrium $(P=0.64$, Table 1$)$. The minor T allele of rs 12255372 was significantly overrepresented in cases, and we found an allelic association with an increased familial BC risk $(\mathrm{OR}=1.19,95 \%$ C.I. $=1.01-1.42, P=0.04$, Table 1$)$. Given the borderline significance, a finding by chance 
cannot be excluded. However, according to the CochranArmitage test for trend the association was allele dosedependent $\left(P_{\text {trend }}=0.04\right.$, Table 1$)$, adding consistency to our data.

The strengths of the present study on BC risk are based on a large sample size and a homogeneous study cohort of a single ethnic group. Only BRCA1/2 mutation-negative familial BC cases were included in order to avoid effects caused by these high-penetrance susceptibility genes. Our study comprised individuals selected for familial BC, since the power of an association study based on cases with a family history of the disease is considerably higher compared to a study using unselected cases [14,15].

This is the first study to investigate TCF7L2 as a candidate gene for cancer susceptibility, suggesting a prominent role of TCF7L2 variants in human cancers, especially in BC. According to Duval et al. [16], mutant TCF7L2 stimulates its transcriptional activity synergistically with $A P C / \beta$-catenin gene alterations. Moreover, it is predicted to show a reduced binding of the C-terminal binding protein (CtBP) which hence loses its capability to repress TCF7L2 activity [17]. Both hypotheses involve an increase of TCF7L2 transcriptional activation, leading to uncontrolled target gene expression. Along the lines of Grant et al. [2] who have ruled out exonic mutations, we assume that the linked repeat polymorphism DG10S478 is causative itself or that DG10S478 and rs12255372 are in strong LD with a functional variant affecting transcription, splicing or message stability.

In summary, our data suggest that TCF7L2 variants may contribute to the risk of familial BC. Regarding the borderline significance level of our results, confirmation in an independent $\mathrm{BC}$ cohort is essential. Moreover, it would be of interest to estimate their impact on further types of human cancer.

\section{Conclusion}

Our data suggest a possible influence of the TCF7L2 rs 12255372 variant on the risk of familial BC.

\section{Abbreviations \\ BC - breast cancer \\ CtBP - C-terminal binding protein}

DHPLC - denaturing high performance liquid chromatography

95\% C.I. - 95\% confidence interval

OR - odds ratio

SNP - single nucleotide polymorphism

TCF7L2 - transcription factor 7-like 2

TCF-4 - HMG box transcription factor 4

\section{Competing interests}

The author(s) declare that they have no competing interests.

\section{Authors' contributions}

$\mathrm{BB}$ designed and coordinated the study and reviewed the manuscript. KSS participated in SNP genotyping. KH participated in the study coordination and revised the manuscript. AM, RKS, CS, BW, MK and CRB collected DNA samples and were responsible for the BRCA1/2 mutation screening. BF conducted the experiments, performed data

Table I: Genotype and allele frequencies of rs 12255372 in unrelated female German BRCAI/2 mutation-negative familial breast cancer (BC) patients and healthy, unrelated female control subjects

\begin{tabular}{|c|c|c|c|}
\hline Genotype & BC Case Patients N (\%) & Control Subjects N (\%) & OR [95\% C.I.], $P$ value \\
\hline GG & $297(50.2)$ & $408(55.5)$ & 1.00 \\
\hline GT & $244(4 I .2)$ & $276(37.6)$ & 1.21 [0.97, I.53], 0.09 \\
\hline TT & $51(8.6)$ & $51(6.9)$ & $1.37[0.91,2.08], 0.13$ \\
\hline $\mathrm{GT}+\mathrm{TT}$ & $295(49.8)$ & $327(44.5)$ & $1.24[1.00,1.54], 0.05$ \\
\hline \multicolumn{4}{|l|}{ Allele } \\
\hline G & 0.71 & 0.74 & 1.00 \\
\hline $\mathrm{T}$ & 0.29 & 0.26 & $1.19[1.01,1.42], 0.04$ \\
\hline
\end{tabular}

a Odds ratios (OR) with $95 \%$ confidence intervals (95\% C.I.) and respective $P$ values were computed by unconditional logistic regression using the Statistical Analysis System software (SAS version 9.1.; SAS Institute Inc., Cary, NC). Adjustment for age did not change the ORs, assuming that the distribution of the TCF7L2 rs 12255372 genotypes is age-independent. 
acquisition and interpretation, and drafted the manuscript. All authors read and approved the final version of the submitted manuscript.

\section{Acknowledgements}

We wish to thank all participants who joined the study and are grateful to Kerstin Wagner and Justo Lorenzo Bermejo for their helpful comments.

The German breast cancer samples were collected within a project funded by the Deutsche Krebshilfe. It was supported by the Center of Molecular Medicine Cologne (CMMC) and the EU, LSHC-CT-2004-503465.

\section{References}

I. Nelson WJ, Nusse R: Convergence of Wnt, beta-catenin, and cadherin pathways. Science 2004, 303:1483-I487.

2. Grant SF, Thorleifsson G, Reynisdottir I, Benediktsson R, Manolescu A, Sainz J, Helgason A, Stefansson H, Emilsson V, Helgadottir A, et al:: Variant of transcription factor 7-like 2 (TCF7L2) gene confers risk of type 2 diabetes. Nat Genet 2006, 38:320-323.

3. van Vliet-Ostaptchouk JV, Shiri-Sverdlov R, Zhernakova A, Strengman E, van Haeften TW, Hofker MH, Wijmenga C: Association of variants of transcription factor 7-like 2 (TCF7L2) with susceptibility to type 2 diabetes in the Dutch Breda cohort. Diabetologia in press. 2006, Oct 10

4. Zhang C, Qi L, Hunter DJ, Meigs JB, Manson JE, van Dam RM, Hu FB: Variant of transcription factor 7-like 2 (TCF7L2) gene and the risk of type 2 diabetes in large cohorts of U.S. women and men. Diabetes 2006, 55:2645-2648.

5. Sjoblom T, Jones S, Wood LD, Parsons DW, Lin J, Barber T, Mandelker D, Leary RJ, Ptak J, Silliman N, et al.: The Consensus Coding Sequences of Human Breast and Colorectal Cancers. Science 2006, 3 | 4:268-274.

6. Wong NA, Pignatelli M: Beta-catenin - a linchpin in colorectal carcinogenesis? Am J Pathol 2002, 160:389-40I.

7. Lin SY, Xia W, Wang JC, Kwong KY, Spohn B, Wen Y, Pestell RG, Hung MC: Beta-catenin, a novel prognostic marker for breast cancer: its roles in cyclin DI expression and cancer progression. Proc Natl Acad Sci U S A 2000, 97:4262-4266.

8. Cowin P, Rowlands TM, Hatsell SJ: Cadherins and catenins in breast cancer. Curr Opin Cell Biol 2005, 17:499-508.

9. Rowlands TM, Pechenkina IV, Hatsell S), Pestell RG, Cowin P: Dissecting the roles of beta-catenin and cyclin $D I$ during mammary development and neoplasia. Proc Natl Acad Sci U S A 2003, I00: I | 400-I I 405.

10. Meindl A, the German Consortium for Hereditary Breast and Ovarian Cancer: Comprehensive analysis of 989 patients with breast or ovarian cancer provides BRCAI and BRCA2 mutation profiles and frequencies for the German population. Int J Cancer 2002, 97:472-480

II. Frank B, Hemminki K, Wappenschmidt B, Klaes R, Meindl A, Schmutzler RK, Bugert P, Untch M, Bartram CR, Burwinkel B: Variable number of tandem repeats polymorphism in the SMYD3 promoter region and the risk of familial breast cancer. Int J Cancer 2006, I 1 8:2917-2918.

I2. Frank B, Hemminki K, Wirtenberger M, Bermejo JL, Bugert P, Klaes R, Schmutzler RK, Wappenschmidt B, Bartram CR, Burwinkel B: The rare ERBB2 variant Ile654Val is associated with an increased familial breast cancer risk. Carcinogenesis 2005, 26:643-647.

13. Dupont WD, Plummer WD Jr: Power and sample size calculations for studies involving linear regression. Control Clin Trials 1998, 19:589-601.

14. Houlston RS, Peto J: The future of association studies of common cancers. Hum Genet 2003, I I 2:434-435.

15. Antoniou AC, Easton DF: Polygenic inheritance of breast cancer: Implications for design of association studies. Genet Epidemiol 2003, 25: 190-202.

16. Duval A, Gayet J, Zhou XP, lacopetta B, Thomas G, Hamelin R: Frequent frameshift mutations of the TCF-4 gene in colorectal cancers with microsatellite instability. Cancer Res 1999, 59:42। $3-4215$.

17. Duval A, Rolland S, Tubacher E, Bui H, Thomas G, Hamelin R: The human T-cell transcription factor-4 gene: structure, extensive characterization of alternative splicings, and mutational analysis in colorectal cancer cell lines. Cancer Res 2000, 60:3872-3879.

Pre-publication history

The pre-publication history for this paper can be accessed here:

http://www.biomedcentral.com/1471-2407/6/268/pre pub
Publish with Biomed Central and every scientist can read your work free of charge

"BioMed Central will be the most significant development for disseminating the results of biomedical research in our lifetime. "

Sir Paul Nurse, Cancer Research UK

Your research papers will be:

- available free of charge to the entire biomedical community

- peer reviewed and published immediately upon acceptance

- cited in PubMed and archived on PubMed Central

- yours - you keep the copyright 